\title{
Investigation of Temperature Rise and Stiffness Experiment of Rolling Bearing under Preload with Oil-Air Lubrication
}

\author{
Li Cui, Wenxia Wang, Xin Jiang, Qingsheng Wang \\ Faculty of Engineering, Shanghai Polytechnic University, China \\ *cuili@sspu.edu.cn
}

Keywords: Intelligent preload; rolling bearing; temperature rising; stiffness

\begin{abstract}
Angular contact ball bearing used in machine tool usually works under high speed and light load condition. Proper preload on bearing can decrease temperature rising and prolong life of bearing. In order to illuminate the effect of preload on thermal and dynamic characteristics of bearing, preload experiment of rolling bearing with oil-air lubrication is studied in this paper. Comparison of position preload, pressure preload, and intelligent preload methods are investigated, results shows that intelligent preload method can ensure high stiffness and low temperature rising of bearing for large range of speed of bearing system.
\end{abstract}

\section{Introduction}

Angular contact ball bearing used in machine tools and other high speed spindles, proper preload on bearing can prevent skidding and gyro rotation phenomenon of ball bearing during the high-speed rotation, which can decrease temperature rising and prolong life of bearing. Normally, there are two ways for bearing preload, radial preload and axial preload[1]. For angular contact ball bearings, position preload and pressure preload method are used widely[2]. Although the above research has offered valuable fundamental data for the rolling bearing lubrication[3], there are still some problems about oil-air lubrication, which are not addressed[4-5]. The effect of preload on temperature rising and stiffness are not clear. The comparative study of the different types of preload on ball bearings under the oil-air lubrication has not been performed[6-7]. The working conditions of the oil air lubrication system are limited.

In this paper, an experiment setup for high speed ball bearings with oil-air lubrication system has been developed. The effects of preload method on the temperature rise and stiffness for ball bearing have been studied.

\section{Experiment of high speed rolling bearing}

Fig.1 shows the schematic view of experiment equipment. The experiment equipment is consisted of high speed spindle bearing system, an air compressor, and oil-air lubrication system. The compressed air is sent into a air reservoir by a filter, and supplied to a oil air distributor. A pump sent the oil to the oil-air mixer. Therefore, the oil and the compressed air are mixed. Under the influence of the compressed air, a continuous oil film is formed gradually inside the oil-air pipes. This film moves in streaks along the inner wall of the oil-air pipe to the test bearings. The oil-air mixture lubricated the bearing at a high rotation speed, and the bearings were lubricated and cooled by oil-air. A pair of tested bearings is back-to-back mounted on a shaft. The left and right bearings can be preloaded.

The rotating speed can be reached to $18000 \mathrm{rpm}$. The temperatures of the bearing outer rings are measured by two thermocouples with an accuracy of $0.1{ }^{\circ} \mathrm{C}$. The displacements of the bearings are measured by two eddy current sensors, then, the sampled data were sent to the computer. Fig. 2 gives the view of the experiment setup. Angular contact ball bearing 7010 is used as test bearing. The oil-air lubrication should be started about 15 min prior to the beginning of the experimenting, which will allow sufficient wetting of the bearing balls and raceways. It took about $30 \mathrm{~min}$ for the bearing to 
reach the thermal equilibrium. In this paper, the bearing temperature rise refers to that of the outer ring. Once the displacement of bearing is obtained, stiffness of bearing can be calculated.

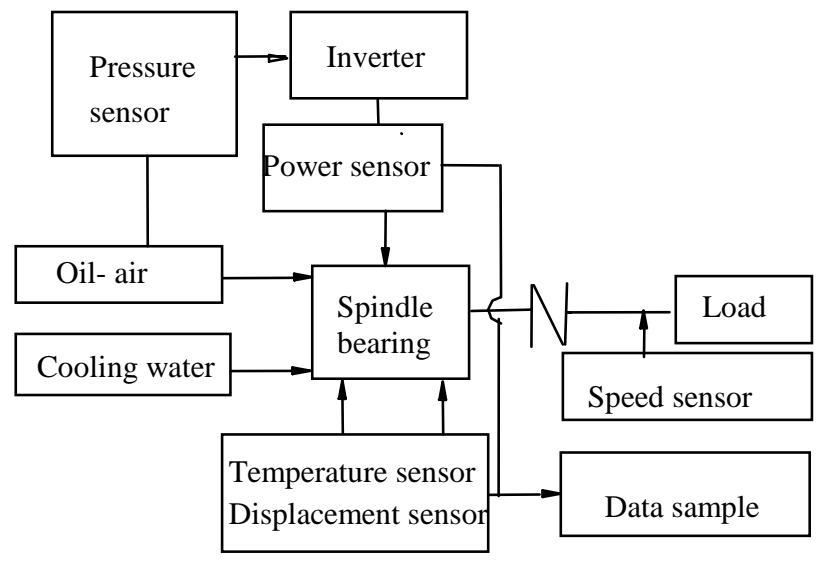

Figure 1. Schematic view of experiment equipment

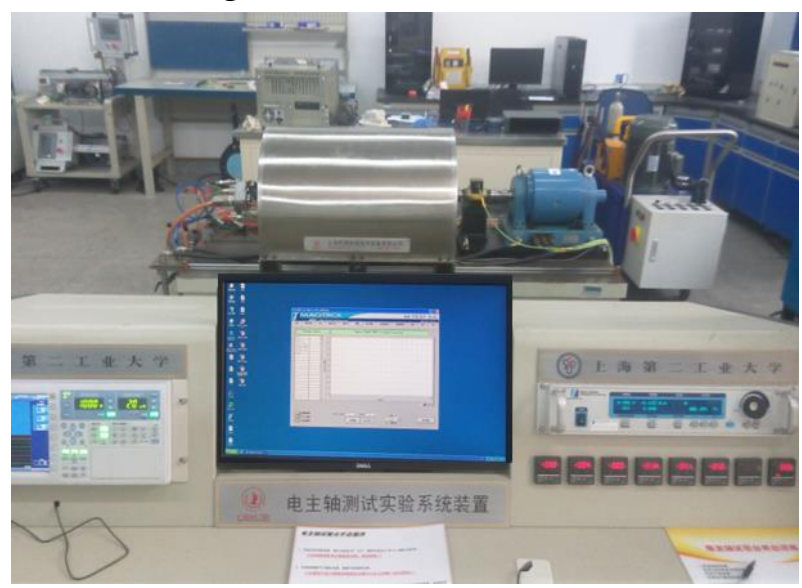

Figure 2. Experiment setup

\section{Results and discussions}

3.1 Position preload. Position preload is obtained by a set of spacer sleeve between the inner ring and the outer ring of the bearing. Under position preload condition, relative position of the bearings will not change. However, the size of the shaft and bearings will be changed because of change of working temperature. Therefore, the preload on bearing will also be changed.

In Fig.3, when there is axial load acting on inner ring of bearing A, the relative displacement of the inner and outer ring of bearings are both $\delta_{\mathrm{a}}$. Considering preload, axial load on bearing A increases, and axial load on bearing B decreases.

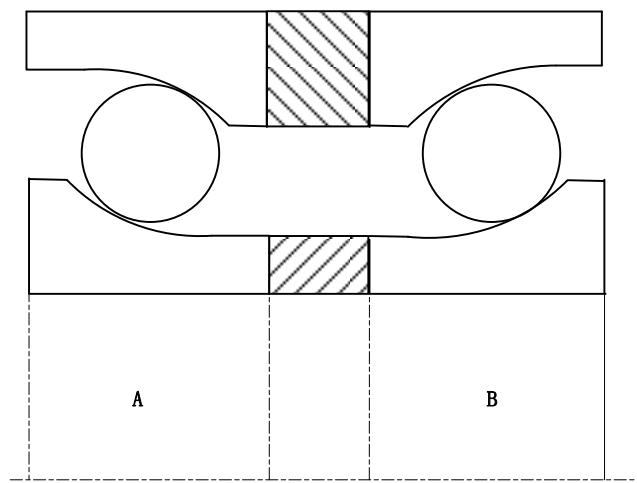

a) Position preload structure

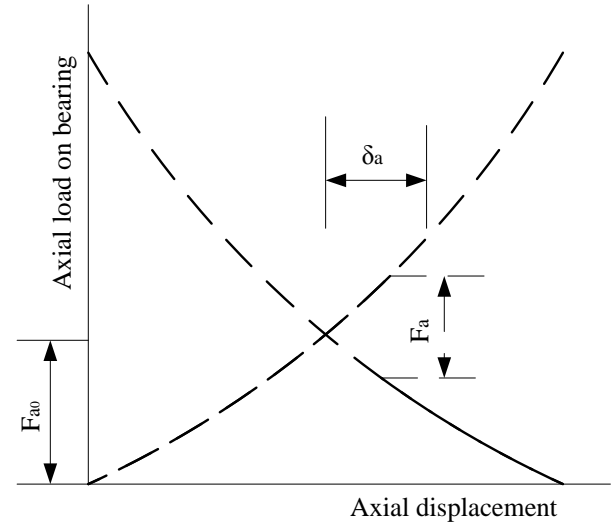

b) displacement-load curve

Figure 3. Position preload and displacement-load curve

Fig.4 shows temperature rising and axial stiffness of bearing B under position preload condition. It can be seen that temperature rising and axial stiffness increase with the increase of rotating speed. When the axial load increases, temperature rising increase but bearing stiffness increases slightly. 


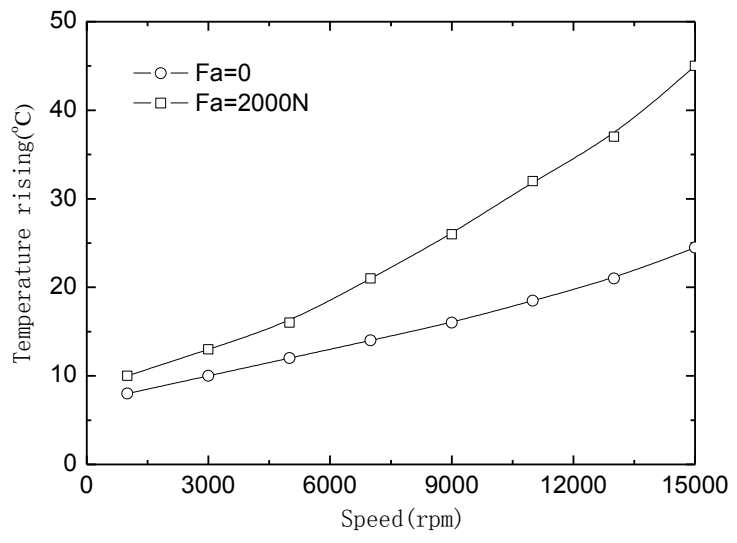

a) Temperature rising

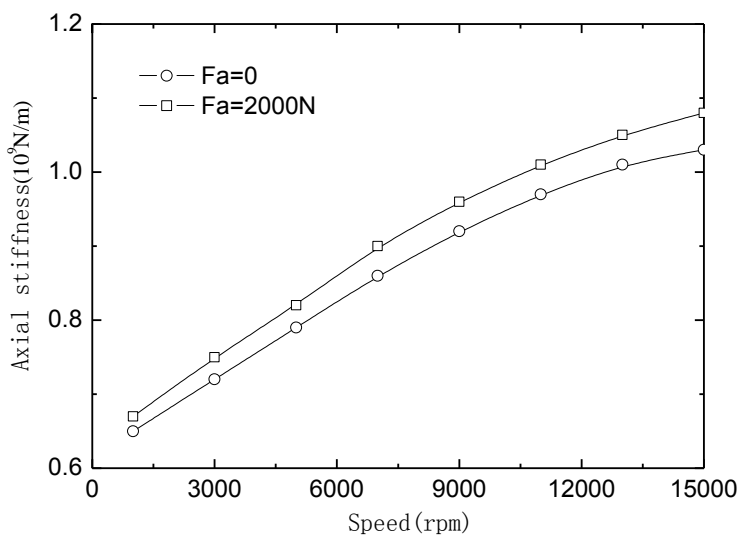

b) Axial stiffness

Figure 4. Temperature rising and stiffness under position preload

3.2 Pressure preload. Pressure preload is obtained by a spiral spring between outer ring of bearing and housing. Under pressure preload condition, relative position of the bearings will change as rotating speed and load. However, the preload will not be changed because it is decided by the spring.

In Fig.5, assuming initial position preload of bearing $A$ and bearing $B$ are $F_{a 0}$. When there is axial load acting on inner ring of bearing $\mathrm{A}$, the relative displacement of the inner and outer ring of bearing $\mathrm{A}$ is $\delta_{\mathrm{a}}$. However, the relative displacement of the inner and outer ring of bearing $\mathrm{A}$ is zero because of stiffness of spring is much less than stiffness of bearing. Therefore, preload on bearing B is not changed.

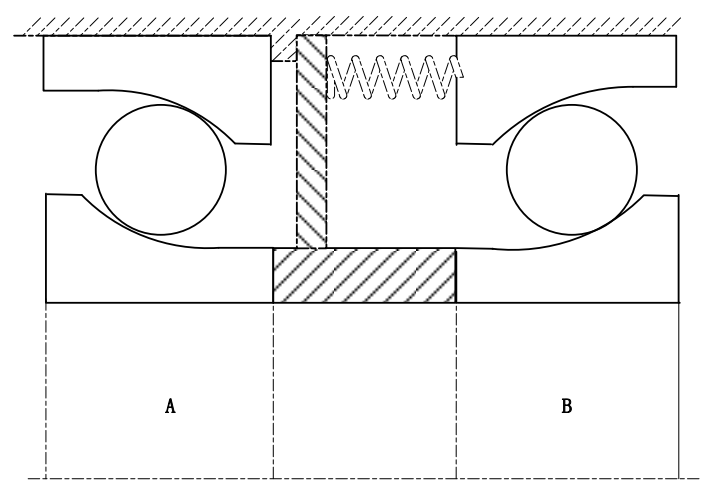

a) Pressure preload structure

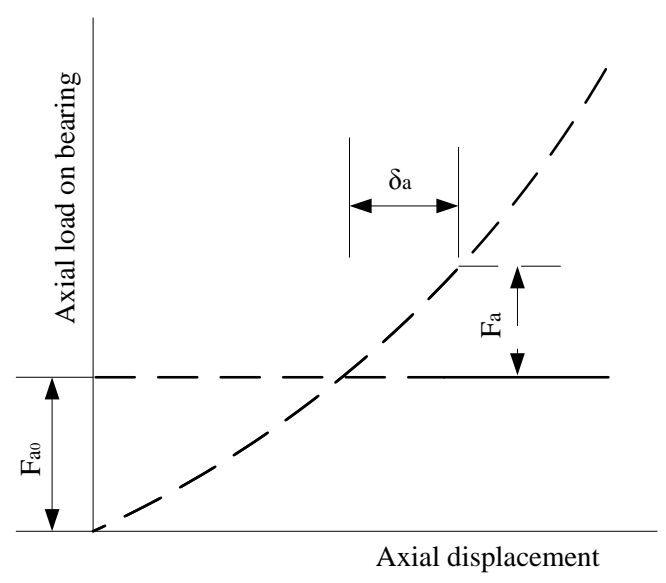

b) displacement-load curve

Figure 5. Pressure preload and displacement-load curve

Fig.6 shows temperature rising and axial stiffness of bearing B under pressure preload condition. It can be seen that temperature rising increases slowly with the increase of rotating speed, and axial stiffness decrease slightly with the increase of rotating speed. When axial load increases, temperature rising increase little but bearing stiffness decreases slightly. 


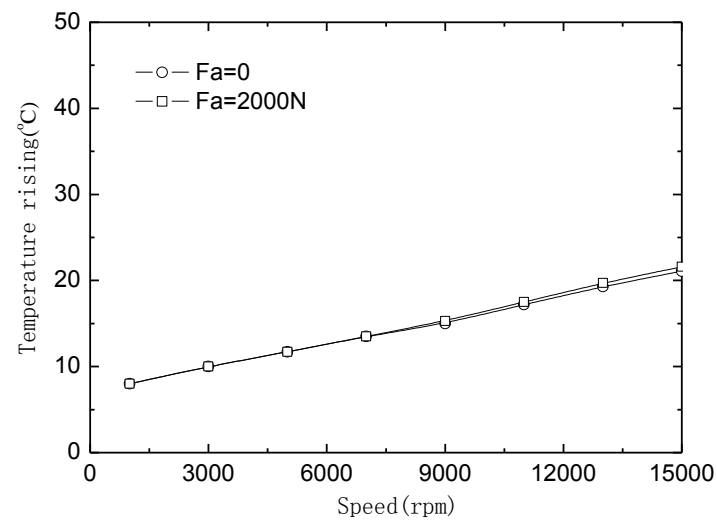

a) Temperature rising

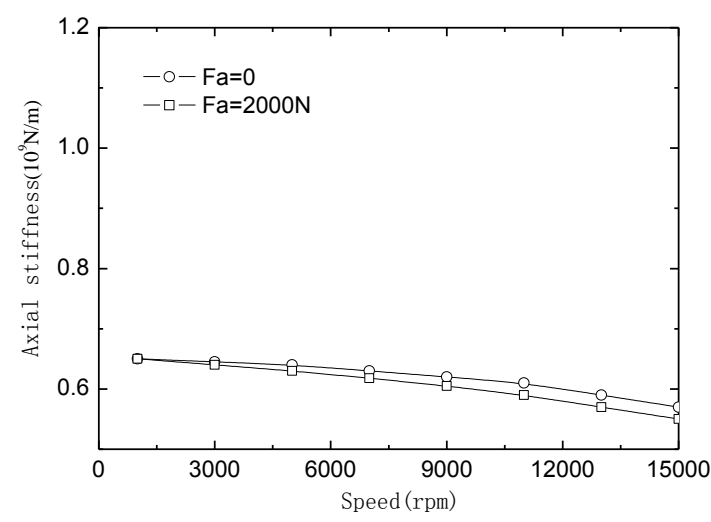

b) Axial stiffness

Figure 6. Temperature rising and stiffness under pressure preload

3.3 Intelligent preload. Intelligent preload is obtained by using a hydraulic cylinder on outer ring of bearing. A hydraulic chamber is used and the preload can be adjusted by pressurizing the internal hydraulic cylindrical preloader. This preloading mechanism is selected here to enable testing with a controlled preload easily.

Under intelligent preload condition, preload of the bearings can be changed as rotating speed and load. Therefore, relative position of the bearings will also be changed. If rotating speed is low, preload can be set as a high value. When rotating speed increase, preload will decrease considering temperature rising of bearings.

Fig.7 shows temperature rising and axial stiffness of bearing B under intelligent preload condition. It can be seen that temperature rising and axial stiffness increase slowly with the increase of rotating speed. When axial load increases, temperature rising and axial stiffness increase little.

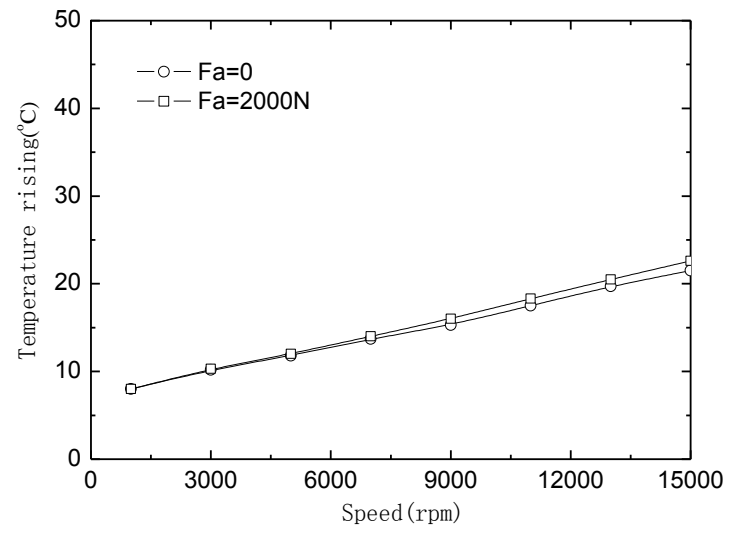

a) Temperature rising

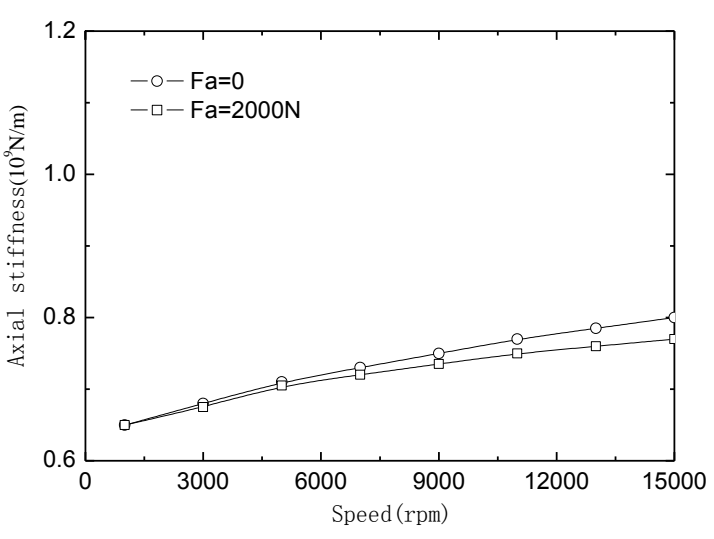

b) Axial stiffness

Figure7. Temperature rising and stiffness under intelligent preload

\section{Conclusions}

Preload of bearing will increase in high speed condition under position preload, which may cause early burn, shorten life of bearings, but stiffness will increase which is benefit for dynamic properties of bearing system. Preload of bearing can keep constant in high speed under pressure preload condition. However, stiffness of bearing will decrease under this condition, which will affect dynamic characteristics of bearing system. For large range of speed of bearing system, in order to ensure high stiffness and low temperature rising of bearing, intelligent preload mode should be considered.

\section{Acknowledgment}

This work was financially supported by Shanghai Natural Science Foundation(No.14ZR1416800), Shanghai Alliance Plan(No. LM201408), National Natural Science Foundation of China (51675323) 
and the key subject of Shanghai Polytechnic University(Material Science and Engineering, XXKZD1601).

\section{References}

[1] Wang Haitong, Li Tiemin, Wang Liping. Research and Application on the Skidding Analysis of the Large Size Ball Bearing. Journal of Mechanical Engineering, 2015,51:41-47.

[2] Li Cui, Yafei He. A new logarithmic profile model and optimization design of cylindrical roller bearing", Industrial Lubrication \& Tribology, 2015, 67:498-508.

[3] Xie, J., Jiang, S. Y., Wang, X. S., and Feng, Y. D. Experimental Research on Oil-Air Lubrication for High Speed Ball Bearing, Lubr. Eng, 2006, 181: 117-119.

[4] J. R. Brown and N. H. Forster. Operating Temperatures in Lubricated Rolling Element Bearings for Gas Turbines, ASME Journal of Tribology, 2000,12: 1268-1275.

[5] E. Creighton, A. Honegger, A. Tulsian, et al. Analysis of thermal errors in a high-speed micro-milling spindle, International Journal of Machine Tools and Manufacture, 2010, 50: 386-393.

[6] Li Cui, Chilan Cai. Nonlinear Dynamics Analysis of a Gear-Shaft-Bearing System with Breathing Crack and Tooth Wear Faults, 2015,9: 483-491.

[7] Li Cui, Jianrong Zheng. Nonlinear vibration and stability analysis of a flexible rotor supported on angular contact ball bearings, Journal of Vibration and Control, 2014, 20: 1767-1782. 